\title{
KESIAPAN AKSESIBILITAS WISATA DALAM MENGINTEGRASIKAN OBYEK WISATA (STUDI KASUS : KARANGANYAR BAGIAN TIMUR)
}

Andreta Hayu Delamartha ${ }^{1)}$, Galing Yudana ${ }^{22}$ Erma Fitria Rini $^{32}$

${ }^{122) 3)}$ Program Studi Perencanaan Wilayah dan Kota, Fakultas Teknik, Universitas Sebelas Maret Surakarta email: andretahayu1998@gmail.com

\begin{abstract}
Abstrak
Pariwisata merupakan sebuah kegiatan dalam rangka memberikan kepuasan atau hiburan terhadap seseorang dan memiliki sifat sementara. Terdapat 5 komponen penting dalam pariwisata atau biasa disebut 5A's tourism, salah satunya adalah Aksesibilitas. Aksesibilitas wisata merupakan segala macam kemudahan yang dapat dirasakan oleh wisatawan dalam melakukan pergerakan/ perpindahan tempat saat perjalanan wisata. Aksesibilitas wisata meliputi 5 hal yaitu Sarana penunjang pariwisata, Prasarana penunjang pariwisata, Informasi mengenai obyek wisata, Waktu, dan Managemen aksesibilitas wisata. Penelitian ini bertujuan untuk mengetahui kesiapan aksesibilitas wisata dalam mengintegrasikan obyek wisata dengan studi kasus di Kabupaten Karanganyar bagian timur. Metode yang digunakan dalam penelitian ini adalah metode penelitian kuantitatif dengan teknik skoring menggunakan Skala Likert. Teknik pengumpulan data dilakukan secara primer dan sekunder melalui survei kuisioner, observasi lapangan, studi literatur, dan studi dokumen dari dinas terkait. Hasil penelitian menunjukkan bahwa penyelenggaraan aksesibilitas wisata di Kabupaten Karanganyar bagian timur dalam mengintegrasikan obyek wisata memiliki tingkat kesiapan yang sedang dengan perolehan skor sebesar 11,06.
\end{abstract}

Kata Kunci: Aksesibilitas Wisata, Integrasi, Kesiapan, Pariwisata,

\begin{abstract}
Tourism is an activity in order to provide satisfaction or entertainment to someone in a temporary period. There are five important components in tourism or commonly called 5A's tourism, one of them is Accesibility. Tourism accessibility is all kinds of conveniences that can be felt by tourists while moving during a tour. Tourism accessibility includes five things, such as tourism support facilities, tourism support infrastructure, and information about tourism objects, time, and tourism accessibility management. This study aims to determine the readiness of tourism accessibility in integrating tourism objects with a case study in the eastern part of Karanganyar Regency. The method used in this research is quantitative research methods with scoring techniques using the Likert Scale. Primary and secondary data collection techniques were carried out through questionnaire surveys, observations, literature studies, and document studies from related agencies. The results showed that the implementation of tourism accessibility in the eastern part of Karanganyar Regency in integrating tourism objects had a moderate level of readiness with a score of 11.06.
\end{abstract}

Keywords: Integration, Readiness, Tourism, Tourism Accessibility,

\section{PENDAHULUAN}

Suwantoro (2004:56) menggolongkan aksesibilitas menjadi salah satu komponen penting dalam penyelenggaraan kegiatan pariwisata hal ini disebabkan karena pengembangan aksesibilitas bersifat lintas sektoral, sehingga komponen aksesibilitas selalu dilibatkan dalam Sapta Kebijakan Pengembangan Pariwisata. Untuk itu, penyelenggaraan aksesibilitas harus 
mendapatkan perhatian lebih khususnya bagi kabupaten/ kota yang menjadikan pariwisata sebagai produk unggulan daerahnya. Salah satu daerah yang menjadikan pariwisata sebagai komoditas unggulan daerah adalah Kabupaten Karanganyar. Kabupaten ini terletak di Provinsi Jawa Tengah dan mulai menjadikan pariwisata sebagai branding daerahnya sejak tahun 1992. Hingga kini Kabupaten Karanganyar dikenal dengan sebutan Bumi INTANPARI (Industri, Pertanian dan Pariwisata).

Berdasarkan RTRW Kabupaten Karanganyar tahun 2013-2032 Pemerintah menetapkan bagian Timur Kabupaten Karanganyar sebagai penggerak utama kegiatan pariwisata alam dan budaya yang berbasis konservasi (RTRW Kabupaten Karanganyar Tahun 2013-2032, 2013). Terdapat 20 obyek wisata yang terdiri dari 5 obyek wisata unggulan dan 15 obyek wisata andalan baik berupa obyek wisata alam, buatan, sejarah maupun religi yang tersebar di bagian Timur Kabupaten Karanganyar seperti pada gambar 1 .

Tidak hanya itu, Kabupaten Karanganyar juga berhasil mendapatkan penghargaan WTN (Wahana Tata Nugraha) yang merupakan bentuk penghargaan dari pemerintah bagi wilayah yang mampu menata transportasi publik dengan baik selama 5 tahun berturutturut dari tahun 2012-2016 (Diskominfo, 2017). Berdasarkan data angkutan orang DISHUB Kabupaten Karanganyar, pada tahun 2020 Kabupaten Karanganyar menyediakan sebanyak 496 unit transportasi publik yang terdiri dari Bus AKAP, AKDP, Bus Pedesaan AKDP, Bus Pariwisata, Angkutan Kota serta Angkutan Pedesaan untuk memudahkan wisatawan dalam melakukan perjalanan wisata dengan transportasi umum.

Namun pada kenyataannya, masih ditemukan banyak masalah pada penyelenggaraan aksesibilitas wisata di Kabupaten Karanganyar bagian timur, diantaranya : masih ditemui sarana dan prasarana yang kondisinya rusak dan terbengkalai (Mantovani, 2021), tidak adanya jadwal keberangkatan angkutan umum yang pasti (Sasmita, 2019), terbatasnya moda angkutan umum yang tersedia disebabkan karena angkutan umum yang masih sering mogok (Setiadi, 2017), minimnya informasi mengenai rute trayek angkutan umum sehingga masih terdapat beberapa angkutan umum yang menyalahi trayek untuk berebut penumpang (Dinas Kominfo Jateng, 2017), serta masih terdapat obyek wisata yang belum dilalui oleh angkutan umum sehingga sulit dijangkau oleh wisatawan (Sumarsono, 2014). Kondisi ini tentunya bertolak belakang dengan prinsip pengembangan pariwisata yang mengharuskan setiap obyek wisata terintegrasi dengan transportasi umum agar memudahkan wisatawan untuk menuju kawasan wisata (Kunjana, 2016).

Tujuan dari penelitian ini adalah untuk mendapatkan gambaran secara rinci mengenai kesiapan aksesibilitas wisata dalam mengintegrasikan obyek wisata khusunya obyek wisata unggulan dan andalan dengan studi kasus Kabupaten Karanganyar bagian Timur melalui analisis pada setiap komponen penyusun aksesibilitas wisata. Penelitian ini juga dapat dijadikan sebagai dasar bagi penelitian mengenai aksesibilitas wisata di masa yang akan datang. Tidak hanya itu, penelitian ini diharapkan dapat menjadi rekomendasi bagi pemerintah Kabupaten Karanganyar khususnya, mengenai komponen aksesibilitas apa saja yang perlu untuk dijadikan sebagai prioritas penanganan agar penyelenggaraan aksesibilitas wisata menjadi lebih optimal dan efisien dalam mengintegrasikan obyek wisata di Kabupaten Karanganyar bagian Timur.

\section{KAJIAN LITERATUR}

\subsection{Definisi Pariwisata}

Pariwisata merupakan kegiatan perjalanan yang dilakukan oleh seorang/ sekelompok orang di daerah lain yang didalamnya mencangkup berbagai kemudahan jasa maupun faktor penunjang lain yang disediakan oleh pemerintah maupun masyarakat agar mampu memenuhi keinginan wisatawan (Hari, 1997). Terdapat 5 komponen penting dalam pariwisata atau biasa dikenal dengan teori Five A's of Tourism Development agar penyelenggaraan pariwisata menjadi lebih optimal, salah satu komponen tersebut 
adalah komponen Aksesibilitas (Spillane, 1987).

\subsection{Definisi Aksesibilitas Wisata}

Aksesibilitas merupakan kemudahan untuk mencapai sesuatu. Aksesibilitas memiliki kaitan yang sangat erat dengan pergerakan. Dalam kegiatan pariwisata, aksesibilitas wisata merupakan berbagai macam kemudahan yang mampu diperoleh pengunjung dalam mengunjungi suatu obyek wisata dan melakukan perpindahan saat sedang melakukan perjalanan wisata. Dalam hal ini, aksesibilitas harus disediakan oleh pemerintah terlepas dari digunakan atau tidaknya oleh masyarakat (Susantoro \& Parikesit, 2004)

\subsection{Komponen Aksesibilitas Wisata}

Aksesibilitas wisata tersusun dari berbagai macam komponen, baik komponen fisik maupun komponen non fisik. Berdasarkan PP No. 50 Tahun 2011 Tentang Rencana Induk Pembangunan Kepariwisataan Nasional Tahun 2010-2025 aksesibilitas dalam wisata meliputi pengembangan sarana dan prasarana transportasi dari berbagai macam angkutan seperti angkutan jalan, sungai, laut, udara serta angkutan kereta api.

Aksesibilitas berhubungan erat dengan waktu. Penelitian Sahla (2017) diketahui bahwa waktu tempuh memiliki kaitan yang sangat erat dengan aksesibilitas dan berpengaruh secara signifikan terhadap minat berkunjung wisatawan. Penyelenggaraan aksesibilitas bagi wisatawan juga mencangkup penyediaan akses informasi wisata yang diwujudkan dengan penyediaan rambu dan informasi yang andal (Simanjuntak et al., 2018).

Penyelenggaraan aksesibilitas juga turut dipengaruhi oleh peran dan keterlibatan pemerintah maupun masyarakat lokal (Wearing \& Mc Donald, 2002) serta dipengaruhi oleh beberapa faktor seperti keamanan, cara pembayaran yang mudah, kenyamanan, kelengkapan fasilitas transportasi umum, serta ketersediaan penyedia aksesibilitas untuk menerima saran dari konsumen (Thynell, 2009).

Sehingga dari beberapa teori di atas dapat diperoleh kesimpulan bahwa komponen dalam aksesibilitas meliputi: Sarana Penunjang Pariwisata, Prasarana Penunjang Pariwisata, Waktu, Informasi mengenai obyek wisata, serta Managemen Aksesibilitas Wisata.

\subsection{Definisi Integrasi Obyek Wisata}

Integrasi berarti sebuah kesatuan. Bowersox et al. (2013)dalam Hamidin \& Surendro (2010) mengelompokkan Integrasi menjadi 4 jenis yaitu integrasi secara fisik, integrasi secara informasi, integrasi secara koordinasi dan integrasi secara rantai produksi.

Berdasarkan teori Strategi Pengembangan Wisata Kota yang Berkelanjutan, beberapa aspek yang harus terintegrasi dalam pembangunan wisata kota ada 4 yairu : Aspek data tarik destinasi, Aspek transportasi, Aspek fasilitas umum dan fasilitas pendukung, serta Aspek kelembagaan (Nations \& Programme, 2005).

\subsection{Definisi Kesiapan}

Kesiapan memiliki arti sudah siap atau sudah sedia. Kesiapan juga diartikan sebagai tingkatan atau keadaan yang menggambarkan kematangan dari suatu keadaan (Chaplin, 2006).

\section{WILAYAH STUDI}

Wilayah studi berada pada Kabupaten Karanganyar di Provinsi Jawa Tengah. Delineasi wilayah studi berada pada 16 Kecamatan yang berada di bagian Timur Kabupaten Karanganyar sesuai dengan pedoman RTRW Kabupaten Karanganyar tahun 2013-2032, dengan batas-batas sebagai berikut :

Bagian Utara : Kab. Sragen

Bagian Selatan : Kab. Wonogiri

Bagian Timur : Kab. Magetan, Jawa Timur

Bagian Barat :Surakarta dan Kab. Wonogiri 




Sumber : Hasil Olahan Peneliti. 2021

Gambar 1 Peta Kawasan Penelitian dan Persebaran Obyek Wisata

\section{METODE PENELITIAN}

Pengumpulan data penelitian diperoleh dari hasil survei kuisioner, observasi lapangan, studi literatur serta studi dokumen dari Dinas terkait. Populasi kuisioner penelitian diambil dari rata-rata jumlah kunjungan wisatawan di obyek wisata andalan dan unggulan di Kabupaten Karanganyar bagian Timur tahun 2016-2018, yaitu sebesar 1.577.943 orang. Penentuan jumlah sampel kuisioner menggunakan metode Slovin dengan rumus:

dimana:

$$
n=\frac{\mathrm{N}}{\left(1+\mathrm{N} \cdot \mathrm{e}^{2}\right)}
$$

$\mathrm{n}=$ jumlah sampel

$\mathrm{N}=$ besarnya populasi

$\mathrm{e}=$ margin error $/$ toleransi

Dengan $\mathrm{e}=10 \%$, diperoleh sampel sebanyak 99,99 orang $\approx 100$ orang dengan menggunakan teknik One Stage Cluster Sampling. Namun, dikarenakan penelitian ini dilakukan pada saat Pandemi COVID-19 dan Masa Pembatasan Sosial Berskala Besar (PSBB) di Jawa Tengah, jumlah responden yang diperoleh hanya sebanyak 81 orang wisatawan yang melakukan kegiatan wisata dengan menggunakan moda transportasi publik.

Metode yang digunakan dalam penelitian ini adalah metode penelitian kuantitatif dengan teknik skoring menggunakan Skala Likert dengan 3 kategori kesiapan yaitu tingkat kesiapan Tinggi (3 poin), Sedang (2 poin) dan Rendah (1 poin).

Penelitian ini terdiri dari 5 Variabel (Sarana Penunjang Pariwisata, Prasarana Penunjang Pariwisata, Waktu, Informasi mengenai obyek wisata, serta Managemen Aksesibilitas Wisata) yang diperinci menjadi 15 sub variabel.

Setiap variabel memiliki bobot yang sama yaitu 1 (satu), walaupun memiliki jumlah sub variabel yang berbeda-beda seperti pada tabel 1. Penghitungan skor setiap sub variabel dapat dihitung dengan rumus:

Bobot sub variabel $n \times$ poin kesiapan $\mathrm{n}$

Perolehan skor total:

Skor Total $=\Sigma$ skor sub variabel 
Berdasarkan rumus di atas, nilai maksimal yang mungkin terbentuk dari hasil skoring adalah 15 sedangkan nilai terendahnya adalah 5, sehingga dapat diperoleh 3 Kategori Kesiapan Aksesibilitas Wisata dalam Mengintegrasikan Obyek Wisata seperti pada tabel 2.
Tabel 2 Kategori Kesiapan Aksesibilitas dalam Mengintegrasikan Obyek Wisata Kategori Kesiapan Interval kelas

Tinggi $11.68-15$

Sedang $\quad 8,34-11,67$

Rendah $5-8,33$

Tabel 1 Skoring Parameter Variabel dan Sub Variabel

\begin{tabular}{|c|c|c|c|c|c|}
\hline \multirow{2}{*}{$\begin{array}{c}\text { Jenis } \\
\text { Integrasi }\end{array}$} & \multirow{2}{*}{$\begin{array}{c}\text { Sub } \\
\text { Variabel }\end{array}$} & \multirow{2}{*}{$\begin{array}{l}\text { Bobot } \\
\text { Sub } \\
\text { Var. }\end{array}$} & \multicolumn{3}{|c|}{ Parameter } \\
\hline & & & $\begin{array}{l}\text { Tinggi } \\
\text { (poin 3) }\end{array}$ & $\begin{array}{l}\text { Sedang } \\
\text { (poin 2) }\end{array}$ & $\begin{array}{l}\text { Rendah } \\
\text { (poin 1) }\end{array}$ \\
\hline & \multicolumn{5}{|c|}{ SARANA PENUNJANG PARIWISATA (Bobot 1) } \\
\hline \multirow[t]{7}{*}{$\begin{array}{c}\text { Integrasi } \\
\text { Fisik }\end{array}$} & $\begin{array}{l}\text { Sarana } \\
\text { Transportasi } \\
\text { umum } \\
\text { mrnuju } \\
\text { DTW }\end{array}$ & 0,16 & $\begin{array}{c}\text { Sudah tersedia } \\
\text { angkutan umum } \\
\text { baik trayek maupun } \\
\text { non trayek yang } \\
\text { mampu melayani } \\
\text { perjalanan } \\
\text { wisatawan menuju } \\
\text { obyek wisata }\end{array}$ & $\begin{array}{l}\text { Hanya tersedia satu } \\
\text { jenis angkutan } \\
\text { umum yang mampu } \\
\text { melayani perjalanan } \\
\text { wisatawan menuju } \\
\text { obyek wisata }\end{array}$ & $\begin{array}{c}\text { Belum tersedia } \\
\text { angkutan Umum } \\
\text { trayek maupun non } \\
\text { trayek yang mampu } \\
\text { melayani perjalanan } \\
\text { wisatawan menuju } \\
\text { obyek wisata }\end{array}$ \\
\hline & $\begin{array}{l}\text { Sarana } \\
\text { Transportasi } \\
\text { Umum dari } \\
\text { dan Menuju } \\
\text { Bandara }\end{array}$ & 0,16 & $\begin{array}{c}\text { Akses menuju } \\
\text { bandar udara dapat } \\
\text { dilayani } \\
\text { transportasi umum } \\
\text { baik angkutan jalan } \\
\text { maupun angkutan } \\
\text { kereta api }\end{array}$ & $\begin{array}{c}\text { Akses menuju } \\
\text { bandar udara hanya } \\
\text { dapat dilayani satu } \\
\text { jenis transportasi } \\
\text { umum }\end{array}$ & $\begin{array}{c}\text { Belum terdapat } \\
\text { transportasi umum } \\
\text { yang mampu } \\
\text { menyediakan akses } \\
\text { menuju bandar } \\
\text { udara }\end{array}$ \\
\hline & $\begin{array}{l}\text { Sarana } \\
\text { Parkir }\end{array}$ & 0,16 & $\begin{array}{c}\text { Jika }>66.6 \% \text { obyek } \\
\text { wisata sudah } \\
\text { memiliki sarana } \\
\text { parkir }\end{array}$ & $\begin{array}{c}\text { Terdapat } 33.3 \%- \\
66.6 \% \text { obyek wisata } \\
\text { yang sudah } \\
\text { memiliki lahan } \\
\text { parkir }\end{array}$ & $\begin{array}{c}\text { Hanya terdapat } \\
<33.3 \% \text { obyek } \\
\text { wisata yang sudah } \\
\text { memiliki lahan } \\
\text { parkir }\end{array}$ \\
\hline & $\begin{array}{l}\text { Terminal } \\
\text { dan bandara }\end{array}$ & 0,16 & $\begin{array}{l}\text { Sudah tersedia } \\
\text { terminal maupun } \\
\text { bandara untuk } \\
\text { mendukung } \\
\text { pergerakan } \\
\text { wisatawan }\end{array}$ & $\begin{array}{c}\text { Hanya tersedia } \\
\text { salah satu diantara } \\
\text { keduanya }\end{array}$ & $\begin{array}{l}\text { Belum tersedia } \\
\text { terminal maupun } \\
\text { bandara untuk } \\
\text { mendukung } \\
\text { pergerakan } \\
\text { wisatawan }\end{array}$ \\
\hline & $\begin{array}{l}\text { Akses } \\
\text { multimoda }\end{array}$ & 0,16 & $\begin{array}{l}\text { Moda terintegrasi } \\
\text { secara penuh antara } \\
\text { angkutan jalan , } \\
\text { angkutan kereta api, } \\
\text { dan angkutan udara }\end{array}$ & $\begin{array}{l}\text { Hanya ada } \\
\text { integrasi antar dua } \\
\text { jenis moda } \\
\text { transportasi }\end{array}$ & $\begin{array}{l}\text { Tidak ada moda } \\
\text { yang terintegrasi }\end{array}$ \\
\hline & $\begin{array}{l}\text { Sarana } \\
\text { transportasi } \\
\text { yang aman, } \\
\text { nyaman dan } \\
\text { mampu } \\
\text { memenuhi } \\
\text { kebutuhan } \\
\text { wisatawan }\end{array}$ & 0,16 & $\begin{array}{l}\text { Tingkat keamanan, } \\
\text { kenyamanan dan } \\
\text { kemampuan moda } \\
\text { transportasi umum } \\
\text { dalam memenuhi } \\
\text { kebutuhan } \\
\text { wisatawan tinggi }\end{array}$ & $\begin{array}{l}\text { Tingkat keamanan, } \\
\text { kenyamanan dan } \\
\text { kemampuan moda } \\
\text { transportasi umum } \\
\text { dalam memenuhi } \\
\text { kebutuhan } \\
\text { wisatawan sedang }\end{array}$ & $\begin{array}{l}\text { Tingkat keamanan, } \\
\text { kenyamanan dan } \\
\text { kemampuan moda } \\
\text { transportasi umum } \\
\text { dalam memenuhi } \\
\text { kebutuhan } \\
\text { wisatawan rendah }\end{array}$ \\
\hline & & PR & NA PENUNJANC & RIWISATA (Bol & \\
\hline
\end{tabular}




\begin{tabular}{|c|c|c|c|c|}
\hline $\begin{array}{l}\text { Jaringan } \\
\text { jalan yang } \\
\text { menghubung } \\
\text { kan obyek } \\
\text { wisata }\end{array}$ & 0.5 & $\begin{array}{c}\text { Seluruh obyek } \\
\text { wisata yang ada } \\
\text { sudah dilalui/ } \\
\text { dilengkapi dengan } \\
\text { jaringan jalan } \\
\end{array}$ & $\begin{array}{c}\text { Masih terdapat } \\
\text { obyek wisata yang } \\
\text { belum dilalui/ } \\
\text { dilengkapi jaringan } \\
\text { jalan }\end{array}$ & $\begin{array}{l}\text { Belum tersedia } \\
\text { jaringan jalan yang } \\
\text { menghubungkan } \\
\text { antar obyek wisata }\end{array}$ \\
\hline $\begin{array}{l}\text { Rute } \\
\text { angkutan } \\
\text { umum yang } \\
\text { menghubung } \\
\text { kan obyek } \\
\text { wisata }\end{array}$ & 0.5 & $\begin{array}{c}\text { Jika rute angkutan } \\
\text { umum sudah } \\
\text { mampu } \\
\text { menjangkau } \\
\text { sebanyak }>66.6 \% \\
\text { dari total obyek } \\
\text { wisata yang ada }\end{array}$ & $\begin{array}{c}\text { Jika rute angkutan } \\
\text { umum hanya } \\
\text { mampu } \\
\text { menjangkau } \\
\text { sebanyak } 33.3 \% \text { - } \\
66.6 \% \text { dari total } \\
\text { obyek wisata yang } \\
\text { ada } \\
\end{array}$ & $\begin{array}{c}\text { Jika rute angkutan } \\
\text { umum hanya } \\
\text { mampu } \\
\text { menjangkau } \\
\text { sebanyak }<33.3 \% \\
\text { dari total obyek } \\
\text { wisata yang ada }\end{array}$ \\
\hline \multicolumn{5}{|c|}{ WAKTU (Bobot 1) } \\
\hline $\begin{array}{l}\text { Waktu } \\
\text { Perjalanan } \\
\text { menuju } \\
\text { DTW }\end{array}$ & 0.5 & $\begin{array}{c}\text { Mayoritas } \\
\text { wisatawan } \\
\text { menghabiskan } \\
\text { waktu selama }<1,5 \\
\text { jam untuk } \\
\text { melakukan } \\
\text { perjalanan wisata } \\
\text { menggunakan } \\
\text { angkutan umum }\end{array}$ & $\begin{array}{c}\text { Mayoritas } \\
\text { wisatawan } \\
\text { menghabiskan } \\
\text { waktu selama } 1,5 \text { - } \\
3 \text { jam untuk } \\
\text { melakukan } \\
\text { perjalanan wisata } \\
\text { menggunakan } \\
\text { angkutan umum }\end{array}$ & $\begin{array}{c}\text { Mayoritas } \\
\text { wisatawan } \\
\text { menghabiskan } \\
\text { waktu selama > } 3 \\
\text { jam untuk } \\
\text { melakukan } \\
\text { perjalanan wisata } \\
\text { menggunakan } \\
\text { angkutan umum }\end{array}$ \\
\hline $\begin{array}{l}\text { Ketepatan } \\
\text { Waktu } \\
\text { kedatangan } \\
\text { Angkutan } \\
\text { Umum }\end{array}$ & 0.5 & $\begin{array}{l}\text { Mayoritas } \\
\text { wisatawan } \\
\text { menghabiskan } \\
\text { waktu selama < 5 } \\
\text { menit untuk } \\
\text { menunggu } \\
\text { kedatangan } \\
\text { angkutan umum }\end{array}$ & $\begin{array}{c}\text { Mayoritas } \\
\text { wisatawan } \\
\text { menghabiskan } \\
\text { waktu selama 5-10 } \\
\text { menit untuk } \\
\text { menunggu } \\
\text { kedatangan } \\
\text { angkutan umum }\end{array}$ & $\begin{array}{c}\text { Mayoritas } \\
\text { wisatawan } \\
\text { menghabiskan } \\
\text { waktu selama >10 } \\
\text { menit untuk } \\
\text { menunggu } \\
\text { kedatangan } \\
\text { angkutan umum }\end{array}$ \\
\hline \multicolumn{5}{|c|}{ INFORMASI OBYEK WISATA (Bobot 1) } \\
\hline $\begin{array}{l}\text { Informasi } \\
\text { yang } \\
\text { memuat } \\
\text { lokasi obyek } \\
\text { wisata }\end{array}$ & 0.5 & $\begin{array}{l}\text { Terdapat rambu } \\
\text { petunjuk arah yang } \\
\text { memuat informasi } \\
\text { kepariwisataan di } \\
\text { seluruh kelas jalan }\end{array}$ & $\begin{array}{c}\text { Rambu petunjuk } \\
\text { arah yang memuat } \\
\text { informasi } \\
\text { kepariwisataan } \\
\text { hanya dapat di } \\
\text { temui di jalan arteri } \\
\text { dan kolektor }\end{array}$ & $\begin{array}{c}\text { Rambu petunjuk } \\
\text { arah yang memuat } \\
\text { informasi } \\
\text { kepariwisataan } \\
\text { hanya dapat di } \\
\text { temui di jalan arteri }\end{array}$ \\
\hline $\begin{array}{l}\text { Pusat } \\
\text { Informasi }\end{array}$ & 0.5 & $\begin{array}{l}\text { Memiliki seluruh } \\
\text { jenis Pusat } \\
\text { Informasi Wisata/ } \\
\text { TIC } \\
\end{array}$ & $\begin{array}{c}\text { Hanya memiliki } \\
\text { beberapa jenis } \\
\text { Pusat Informasi } \\
\text { Wisata/ TIC }\end{array}$ & $\begin{array}{c}\text { Sama sekali belum } \\
\text { memiliki Pusat } \\
\text { Informasi Wisata/ } \\
\text { TIC }\end{array}$ \\
\hline \multicolumn{5}{|c|}{ MANAGEMEN AKSESIBILITAS WISATA (Bobot 1) } \\
\hline $\begin{array}{l}\text { Stake holder } \\
\text { terkait }\end{array}$ & 0,33 & $\begin{array}{l}\text { Jika pemerintah } \\
\text { melakukan semua } \\
\text { perannya berupa } \\
\text { penyusunan } \\
\text { program, } \\
\text { pelaksanaan } \\
\text { kegiatan serta } \\
\text { pengawsan }\end{array}$ & $\begin{array}{c}\text { Jika pemerintah } \\
\text { melakukan } \\
\text { perannya berupa } \\
\text { penyusunan } \\
\text { program, } \\
\text { pelaksanaan } \\
\text { kegiatan namun } \\
\text { belum melakukan } \\
\text { pengawasan }\end{array}$ & $\begin{array}{c}\text { Jika pemerintah } \\
\text { hanya sebatas } \\
\text { melakukan } \\
\text { penyusunan } \\
\text { program, namun } \\
\text { belum sampai pada } \\
\text { tahap pelaksanaan } \\
\text { kegiatan serta } \\
\text { pengawasan }\end{array}$ \\
\hline Pembiayaan & 0,33 & $\begin{array}{c}\text { Jika terdapat } \\
\text { pembiayaan dalam } \\
\text { pengelolaan }\end{array}$ & $\begin{array}{l}\text { Jika terdapat } \\
\text { pembiayaan namun } \\
\text { hanya }\end{array}$ & $\begin{array}{l}\text { Jika belum terdapat } \\
\text { pembiayaan yang } \\
\text { dialokasikan khusus }\end{array}$ \\
\hline
\end{tabular}




\begin{tabular}{|c|c|c|c|c|}
\hline & & $\begin{array}{c}\text { aksesibilitas wisata } \\
\text { dan berasal dari } \\
\text { berbagai sumber } \\
\text { baik dari APBD, } \\
\text { investasi/ } \\
\text { penanaman modal } \\
\text { dan sumber lainnya }\end{array}$ & $\begin{array}{l}\text { mengandalkan } \\
\text { pembiayaan yang } \\
\text { bersumber dari } \\
\text { APBD }\end{array}$ & $\begin{array}{l}\text { untuk pengelolaan } \\
\text { aksesibilitas wisata }\end{array}$ \\
\hline $\begin{array}{l}\text { Partisipasi } \\
\text { Masyarakat }\end{array}$ & 0,33 & $\begin{array}{c}\text { Masyarakat sudah } \\
\text { terlibat dalam } \\
\text { segala bentuk } \\
\text { partisipasi (ide, } \\
\text { tenaga, maupun } \\
\text { keahlian) dalam } \\
\text { penyelenggaraan } \\
\text { aksesibilitas wisata }\end{array}$ & $\begin{array}{l}\text { Masyarakat sudah } \\
\text { terlibat dalam } \\
\text { beberapa bentuk } \\
\text { partisipasi (ide, } \\
\text { tenaga, maupun } \\
\text { keahlian) dalam } \\
\text { penyelenggaraan } \\
\text { aksesibilitas wisata }\end{array}$ & $\begin{array}{c}\text { Masyarakat sama } \\
\text { sekali belum } \\
\text { terlibat dalam } \\
\text { segala bentuk } \\
\text { partisipasi (ide, } \\
\text { tenaga, tenaga dan } \\
\text { ide, maupun } \\
\text { keahlian) dalam } \\
\text { penyelenggaraan } \\
\text { aksesibilitas wisata }\end{array}$ \\
\hline
\end{tabular}

\section{HASIL DAN PEMBAHASAN}

\subsection{Analisis ketersediaan sarana penunjang pariwisata}

\subsubsection{Ketersediaan sarana transportasi umum menuju Daya Tarik Wisata}

Sudah tersedia transportasi umum baik trayek maupun non trayek di Kabupaten Karanganyar bagian timur berupa Bus AKDP 78 unit, Bus AKAP 120 unit, Angkutan Kota 114 unit dan Angkutan Pedesaan sebanyak 136 unit. Transportasi umum non trayek di kawasan ini berupa Bus Pariwisata 48 unit dan angkutan para transit seperti ojek pengkolan maupun ojek online. Sehingga berdasarkan parameter pada tabel 1 , sub variabel sarana transportasi umum menuju DTW mendapatkan poin 3 yang artinya memiliki tingkat kesiapan yang tinggi.

\subsubsection{Ketersediaan sarana transportasi umum dari dan menuju bandara}

Akses dari Kabupaten Karanyanyar bagian timur menuju ke bandara terdekat (Bandara Adi Soemarmo) hanya dapat diakses menggunakan moda angkutan jalan (bus dan angkutan para transit) saja. Hal ini disebabkan karena belum aktifnya pengoperasian Stasiun Kereta Api Palur sehingga akses dari kawasan studi menuju bandara belum mampu diintegrasikan dengan menggunakan kereta api. Oleh sebab itu, berdasarkan parmeter pada tabel 1 , sub variabel sarana transportasi umum dari dan menuju bandara hanya mendapatkan
2 poin yang artinya memiliki tingkat kesiapan yang sedang.

\subsubsection{Ketersediaan sarana parkir}

Dari 20 obyek wisata unggulan dan andalan yang ada di Kabupaten Karanganyar bagian timur, hanya terdapat 2 obyek wisata yang belum dilengkapi dengan sarana parkir yaitu Situs Watukandang dan Pertapaan Pringgondani. Kedua obyek wisata tersebut masih menggunakan badan jalan dan open space seadanya sebagai tempat parkir. Dengan kata lain, terdapat lebih dari $66,6 \%$ obyek wisata yang sudah dilengkapi dengan sarana parkir seperti pada gambar 2. Berdasarkan parameter pada tabel 1, sub variabel Sarana Parkir mendapatkan poin maksimal yaitu 3 yang artinya memiliki kesiapan yang tinggi

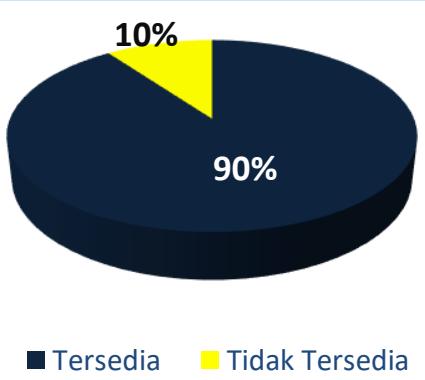

Gambar 2 Diagram Ketersediaan Sarana Parkir di Obyek Wisata di Kabupaten Karanganyar bagian Timur 


\subsubsection{Ketersediaan terminal dan bandara}

Berdasarkan hasil analisis yang sudah dilakukan, Kabupaten Karanganyar bagian timur sudah dilengkapi dengan 10 unit terminal ( 8 Terminal tipe $\mathrm{B}$ dan $\mathrm{C}$ dan 2 terminal wisata) serta 1 stasiun kereta api untuk memfasilitasi pergerakan wisatawan saat melakukan kegiatan wisata. Persebaran terminal, stasiun dan bandara dapat dilihat pada gambar 3 .
Kabupaten Karanganyar bagian Timur belum dilengkapi dengan bandara, sehingga wisatawan yang akan melakukan perjalanan wisata dengan menggunakan angkutan udara, harus melakukan perpindahan moda di 2 bandara terdekat dari kawasan studi yairu Bandara Adisumarmo (Boyolali) atau Bandara Adisucipto (Yogyakarta). Oleh sebab itu, sesuai dengan parameter tabel 1 , sub variabel Terminal dan Bandara hanya mendapatkan 2 poin atau dengan kata lain memiliki tingkat kesiapan sedang.

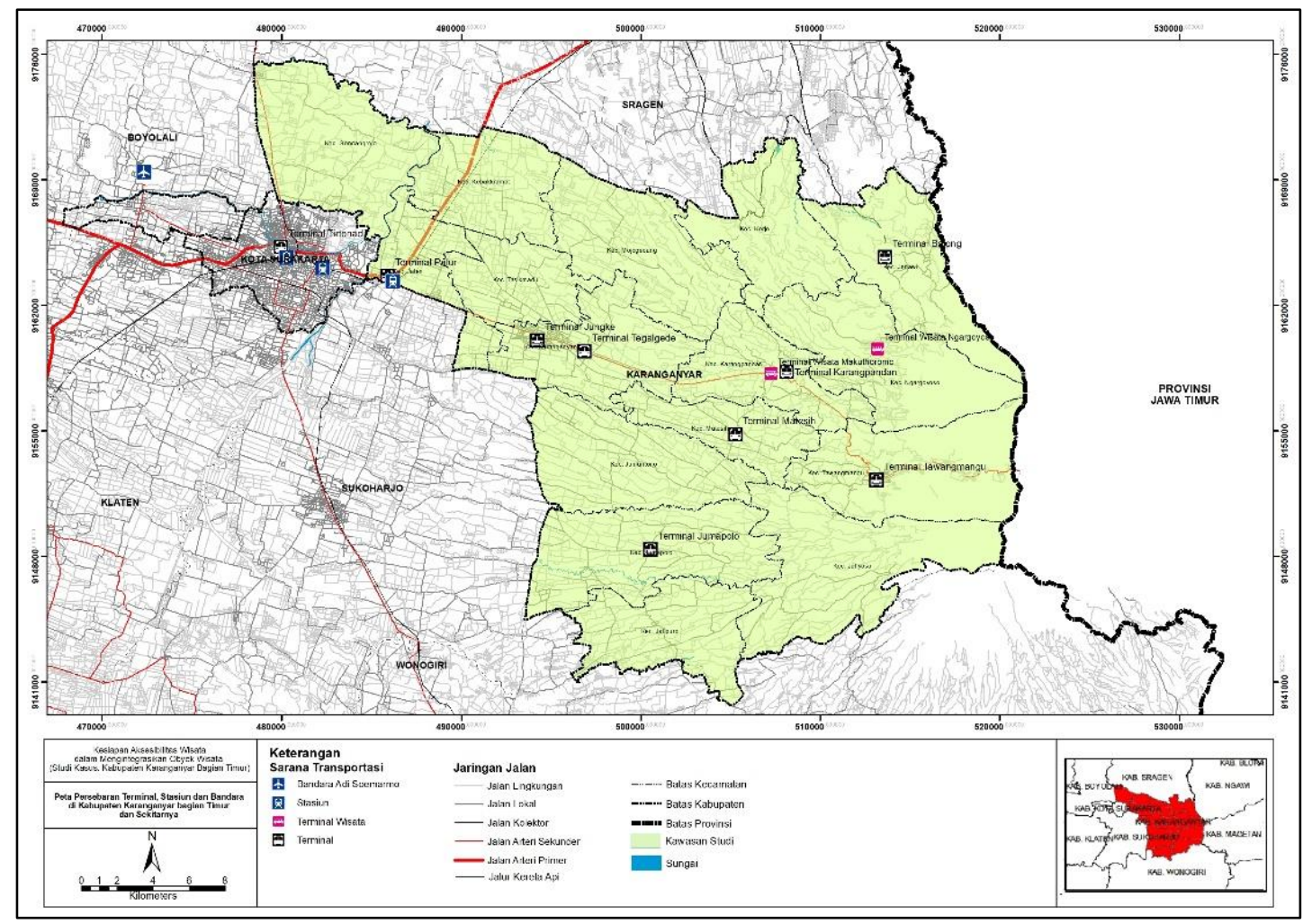

Sumber: Hasil Analisa, 2021

\section{Gambar 3 Peta Persebaran Terminal, Stasiun dan Bandara}

\subsubsection{Ketersediaan akses multimoda}

Penyelenggaraan akses multimoda secara kompleks (gabungan antar moda angkutan jalan, angkutan kereta api dan angkutan udara) justru terbentuk di luar Kawasan Kabupaten Karanganyar bagian Timur seperti pada gambar 4 .

Akses multimoda di Kabupaten Karanganyar bagian timur hanya terbetuk dari integrasi antar angkutan jalan saja, seperti Bus, Angkutan Kota, Angkutan Pedesaan, serta angkutan paratransit, sehingga cukup menyulitkan wisatawan untuk melakukan pergerakan. Kurangnya integrasi antar moda transportasi di kawasan ini disebabkan karena belum berfungsinya Stasiun KA Palur secara optimal dan kondisi topografi Kabupaten Karanganyar yang berada di Lereng Gunung Lawu dengan kemiringan 15\% - 40\% sehingga tidak bisa dijangkau oleh beberapa jenis moda transportasi umum. Berdasarkan hasil analisis di atas sub variabel Akses multimoda di Kabupaten Karanganyar hanya mendapatkan 1 poin yang artinya memiliki tingkat kesiapan yang Rendah. 




Sumber: Hasil Analisa, 2021

Gambar 4 Skema akses multimoda di Kabupaten Karanganyar bagian Timur dan Sekitarnya

\subsubsection{Sarana transportasi umum yang mampu menciptakan rasa aman, nyaman dan memenuhi kebutuhan wisatawan}

Berdasarkan hasil survei kuisioner yang diisi oleh 81 wisatawan yang berwisata dengan menggunakan moda transportasi umum di Kabupaten Karanganyar terhadap 6 pertanyaan, meliputi:

$\mathrm{X}_{1}=$ Kemampuan angkutan umum dalam menciptakan rasa aman

$\mathrm{X}_{2}=$ Kelengkapan fasilitas keamanan dalam angkutan umum

$\mathrm{X}_{3}=$ Tingkat kebersihan angkutan umum

$\mathrm{X}_{4}=$ Tingkat kelayakan angkutan umum untuk dioperasikan

$\mathrm{X}_{5}=$ Ketersediaan pengelola angkutan umum untuk menerima masukan dari wisatawan

$\mathrm{X}_{6}=$ Kemudahan dalam metode pembayaran

Diperoleh skor total sebesar 824 poin yang masuk ke dalam kategori kesiapan Sedang seperti pada tabel 3.

Sehingga berdasarkan parameter pada tabel 1, Kesiapan Kabupaten Karanganyar dalam menyediakan angkutan umum yang aman dan nyaman bagi wisatawan masih Sedang, sehingga sub variabel ini hanya mendapatkan skor sebesar 2 poin.

Tabel 3 Rekapitulasi Hasil Survei Kuisoner Survei

\begin{tabular}{ccccc}
\hline Kode & Skor 3 & Skor 2 & Skor 1 & \\
Pertanyaan Tinggi & Sedang & Rendah & Jumlah \\
\hline $\mathrm{X}_{1}$ & 29 & 46 & 6 & 81 \\
\hline $\mathrm{X}_{2}$ & 1 & 21 & 59 & 81 \\
\hline
\end{tabular}

\begin{tabular}{|c|c|c|c|c|}
\hline$X_{3}$ & 21 & 21 & 39 & 81 \\
\hline $\mathrm{X}_{4}$ & 25 & 52 & 4 & 81 \\
\hline$X_{5}$ & 1 & 40 & 40 & 81 \\
\hline $\mathrm{X}_{6}$ & 0 & 4 & 77 & 81 \\
\hline \multirow[t]{2}{*}{ total } & 77 & 184 & 225 & \\
\hline & 231 & 368 & 225 & \\
\hline total skor & 824 & & & \\
\hline
\end{tabular}

\subsection{Analisis ketersediaan prasarana penunjang pariwisata}

5.2.1. Ketersediaan jaringan jalan yang menghubungkan obyek wisata

Seluruh obyek wisata baik unggulan maupun andalan di Kabupaten Karanganyar bagian Timur sudah diintegrasikan dengan jaringan jalan, baik jalan arteri, kolektor, lokal maupun lingkungan. Karakteristik jalan di kabupaten Karanganyar berkelok kelok dan cukup curam karena berada di lereng Gunung Lawu dengan kemiringan 15 - 40\% sehingga di berbagai titik dilengkapi sarana keamanan seperti kaca pembesar, guard rill, serta adanya kebijakan larangan bagi angkutan umum besar (bus) untuk menuju beberapa obyek wisata seperti Candi Sukuh dan Candi Cetho dalam upaya meminimalisir terjadinya kecelakaan lalu lintas. Berdasarkan parameter tabel 1, Kesiapan jaringan jalan di Kabupaten Karanganyar dalam mengintegrasikan obyek wisata mendapat 3 poin (Tinggi).

\subsubsection{Ketersediaan dan jangkauan rute trayek angkutan umum}

Angkutan umum trayek yang ada di Kabupaten Karanganyar bagian Timur berupa 
Angkutan Kota, Angkutan Pedesaan, Bus AKDP, dan Bus AKAP. Dari 20 obyek wisata yang ada, sebanyak $35 \%$ obyek wisata sama sekali tidak terjangkau oleh layanan angkutan umum sedangkan $65 \%$ sudah dijangkau dengan angkutan umum dengan rincian sebagai berikut :

- Sebanyak 40\% obyek wisata hanya dilayani oleh 1 rute trayek angkutan umum,

- Sebanyak $15 \%$ obyek wisata dilayani oleh 2 rute trayek angkutan umum, dan

- Sebanyak $10 \%$ obyek wisata dilayani dan dijangkau oleh seluruh moda transportasi trayek yang ada di kabupaten Karanganyar bagian Timur

Berdasarkan pada parameter tabel 1 dan hasil analisis di atas, Kemampuan Kabupaten Karanganyar bagian timur dalam menyediakan moda transportasi umum untuk menjangkau dan mengintegrasikan obyek wisata unggulan dan andalan yang ada masih Sedang sehingga hanya mendapatkan 2 poin.



Sumber: Hasil Analisa, 2021

Gambar 5 Prosentase Obyek Wisata yang Dilalui oleh Trayek Transportasi Umum

\subsection{Analisis waktu yang dibutuhkan wisatawan untuk melakukan perjalanan wisata}

\subsubsection{Waktu perjalanan menuju DTW}

Berdasarkan hasil survei kuisioner terhadap 81 wisatawan yang melakukan perjalanan wisata dengan menggunakan transportasi umum di Kabupaten Karanganyar bagian Timur diperoleh hasil bahwa 76,54\% wisatawan menghabiskan waktu kurang dari 1,5 jam untuk melakukan perjalanan, selanjutnya sebanyak $22,22 \%$ menghabiskan waktu selama 1,5-3 jam, dan sisanya sebesar
$1,23 \%$ wisatawan harus menghabiskan waktu lebih dari 3 jam hanya untuk melakukan perjalanan menggunakan moda transportasi umum seperti yang tampak pada gambar 6 . Berdasarkan hasil analisis di atas, sub variabel waktu perjalanan menuju DTW mendapatkan poin tinggi yaitu 3 .

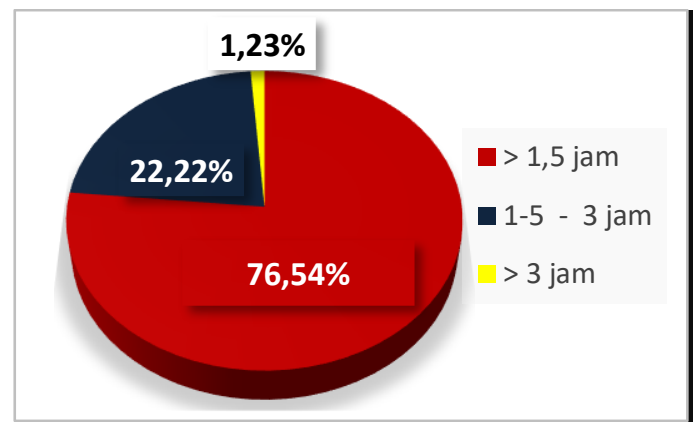

Sumber: Hasil Analisa, 2021

Gambar 6 Prosentase Waktu yang Dihabiskan Wisatawan untuk Melakukan Perjalanan Wisata dengan Transportasi Umum

\subsubsection{Ketepatan waktu kedatangan angkutan umum}

Berdasarkan hasil survei kuisioner terhadap 81 wisatawan yang melakukan perjalanan wisata dengan menggunakan transportasi umum di Kabupaten Karanganyar bagian Timur diperoleh hasil bahwa mayoritas wisatawan atau sebesar 44,44\% menghabiskan waktu lebih dari 10 menit hanya untuk menunggu kedatangan angkutan umum, $29,62 \%$ menunggu selama 5 - 10 menit dan sisanya hanya sekitar $25,92 \%$ yang menunggu kurang dari 5 menit seperti yang ada pada gambar 7. Kondisi ini menyebabkan sub variabel ini mendpatkan nilai Rendah yaitu 1 poin.

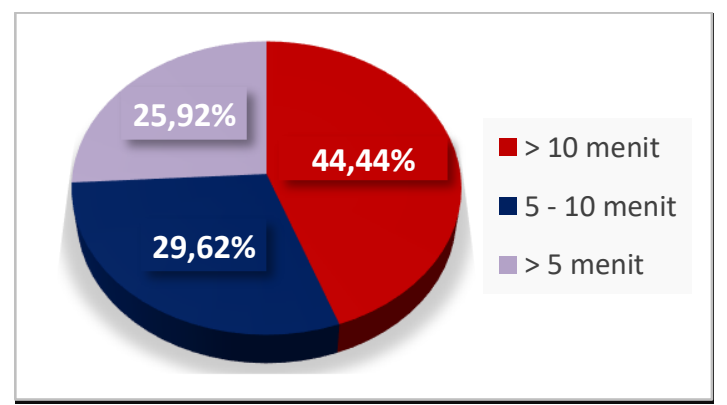

Sumber: Hasil Analisa, 2021

Gambar 7 Prosentase Ketepatan Waktu Kedatangan Transportasi Umum 


\subsection{Analisis ketersediaan informasi mengenai obyek wisata}

\subsubsection{Ketersediaan rambu petunjuk arah}

Seluruh Kawasan Kabupaten

Karanganyar bagian Timur sudah dilengkapi oleh papan informasi yang memuat informasi mengenai obyek wisata. Seluruhnya tersebar baik di sepanjang jalan arteri, kolektor maupun jalan lokal dengan total sebanyak 49 unit. Hal ini membuktikan bahwa Kesiapan Aksesibilitas wisata dalam hal penyediaan rambu petunjuk arah untuk membantu wisatawan dalam melakukan perjalanan berdasarkan parameter pada tabel 1 adalah tinggi sehingga mendapatkan nilai 3 .

\subsubsection{Keyersediaan pusat informasi (TIC)}

Kabupaten Karanganyar hanya memiliki 2 dari 3 jenis TIC yang harus disediakan oleh pemerintah bagi daerah yang ingin mengembangkan sector pariwisata. Kedua TIC tersebut yaitu TIC yang terletak di gerbang keberangkatan wisata (TIC Makuthoromo) dan TIC yang terletak di dalam kawasan obyek wisata (Lawu Information Centre). Oleh sebab itu, berdasarkan hasil analisis tersebut, kesiapan aksesibilitas wisata di Kabupaten Karanganyar dalam hal penyediaan TIC masih sedang sehingga hanya mendapatkan 2 poin

\subsection{Analisis ketersediaan manajemen aksesibilitas wisata}

\subsubsection{Peran dan keteribatan stakeholder dalam mengelola aksesibilitas wisata}

Stakeholder yang berkaitan erat dengan penyelenggaraan aksesibilitas wisata di Kabupaten Karanganyar bagian Timur adaah DISHUB-PKP dan DISPARPORA. Berdasarkan hasil analisis terhadap dokumen capaian target kinerja lembaga pemerintah pada tahun 2018, kedua Dinas terkait sudah mampu melaksanakan seluruh tugasnya. Namun kedua Dinas tersebut belum maksimal dalam melakukan fungsi pengawasan.

Hal ini ditandai dengan adanya sarana dan prasarana di obyek wisata yang mulai rusak, masih terdapat obyek wisata yang belum memiliki lahan parkir, belum mampunya angkutan umum dalam memberikan kenyamanan, kemanan dan memenuhi kebutuhan wisatawan, masih terdapat beberapa obyek wisata yang belum dijangkau angkutan umum, kurangnya kualitas pelayanan terkait informasi wisata di TIC, serta terdapat beberapa komponen aksesibilitas wisata yang terbengkalai namun dibiarkan begitu saja. Oleh sebab itu sub variabel ini memiliki kesiapan yang sedang dengan perolehan 2 poin.

\subsubsection{Ketersediaan pembiayaan untuk pengelolaan aksesibilitas wisata}

Sumber pembiayaan untuk pengelolaan Aksesibilitas wisata hanya bersifat Top Down, yang berasal dari APBD Kabupaten Karanganyar tahun 2018, tepatnya dari Dana Alokasi Khusus APBD Tahun anggaran 2018 sebesar Rp 2.586.200.000,00. Hal ini secara tidak langsung sangat berdampak pada keberlanjutan program-program penyelenggaraan aksesibilitas yang ada. Oleh karena itu, sub variabel pembiayaan juga hanya mendapatkan 2 poin dengan tikat kesiapan yang sedang.

\subsubsection{Community Involment}

Keterlibatan masyarakat lokal dalam penyelenggaraan aksesibilitas di Kabupaten Karnganyar bagian Timur hanya sebatas keterlibatan dalam hal tenaga. Hal ini dibuktikan dengan adanya masyarakat yang bekerja sebagai Tukang ojek di kaawasan wisata, SUPELTAS, Tukang parkir, bahkan guide dan porter untuk pendakian Gunung Lawu. Berdasarkan hasil analisis di atas, kesiapan masyarakat dalam hal keterlibatannya dalam penyelenggaraan aksesibilitas di kabupaten karanganyar hanya mendapatkan 2 poin atau sedang

\subsection{Hasil analisis skoring kesiapan aksesibilitas wisata di Kabupaten Karanganyar bagian Timur dalam mengintegrasikan obyek wisata}

Hasil analisis skoring mengenai kesiapan aksesibilitas wisata di Kabupaten Karanganyar bagian Timur dapat dilihat pada tabel 4 . 


\section{Tabel 4 Hasil Analisis Skoring Kesiapan Aksesibilitas Wisata di Kabupaten Karanganyar bagian Timur dalam Mengintegrasikan Obyek Wisata}

\begin{tabular}{|c|c|c|c|c|c|c|}
\hline $\begin{array}{c}\text { Jenis } \\
\text { Integrasi }\end{array}$ & Variabel & Bobot & Sub Variabel & $\begin{array}{c}\text { Bobot } \\
\text { Sub } \\
\text { Variabel }\end{array}$ & Skor & $\begin{array}{l}\text { Total } \\
\text { Skor }\end{array}$ \\
\hline \multirow{10}{*}{$\begin{array}{l}\text { Integrasi } \\
\text { Fisik }\end{array}$} & \multirow{6}{*}{$\begin{array}{l}\text { Sarana } \\
\text { Penunjang } \\
\text { Wisata }\end{array}$} & \multirow{6}{*}{1} & $\begin{array}{l}\text { Sarana Transportasi umum menuju } \\
\text { DTW }\end{array}$ & 0,16 & 3 & 0,48 \\
\hline & & & $\begin{array}{l}\text { Sarana Transportasi Umum dari dan } \\
\text { Menuju Bandara }\end{array}$ & 0,16 & 2 & 0,32 \\
\hline & & & Sarana Parkir & 0,16 & 3 & 0,48 \\
\hline & & & Terminal dan Bandara & 0,16 & 2 & 0,32 \\
\hline & & & Akses multimoda & 0,16 & 1 & 0,16 \\
\hline & & & $\begin{array}{l}\text { Sarana transportasi yang aman, nyaman } \\
\text { dan mampu memenuhi kebutuhan } \\
\text { wisatawan }\end{array}$ & 0,16 & 2 & 0,32 \\
\hline & \multirow{2}{*}{$\begin{array}{l}\text { Prasarana } \\
\text { Penunjang } \\
\text { Wisata }\end{array}$} & \multirow[b]{2}{*}{1} & $\begin{array}{l}\text { Jaringan jalan yang menghubungkan } \\
\text { obyek wisata }\end{array}$ & 0.5 & 3 & 1,5 \\
\hline & & & $\begin{array}{l}\text { Rute angkutan umum yang } \\
\text { menghubungkan obyek wisata }\end{array}$ & 0.5 & 2 & 1 \\
\hline & \multirow[b]{2}{*}{ Waktu } & \multirow[b]{2}{*}{1} & Waktu Perjalanan menuju DTW & 0.5 & 3 & 1,5 \\
\hline & & & $\begin{array}{l}\text { Ketepatan Waktu kedatangan Angkutan } \\
\text { Umum }\end{array}$ & 0.5 & 1 & 0,5 \\
\hline \multirow{2}{*}{$\begin{array}{l}\text { Integrasi } \\
\text { Informasi }\end{array}$} & \multirow{2}{*}{$\begin{array}{l}\text { Informasi } \\
\text { Obyek } \\
\text { wisata }\end{array}$} & \multirow[t]{2}{*}{1} & $\begin{array}{l}\text { Informasi yang memuat lokasi obyek } \\
\text { wisata }\end{array}$ & 0.5 & 3 & 1,5 \\
\hline & & & Pusat Informasi & 0.5 & 2 & 1 \\
\hline \multirow{3}{*}{$\begin{array}{c}\text { Integrasi } \\
\text { Managemen }\end{array}$} & \multirow{3}{*}{$\begin{array}{c}\text { Manajemen } \\
\text { Aksesibilitas } \\
\text { Wisata }\end{array}$} & \multirow{3}{*}{1} & Stake holder terkait & 0,33 & 2 & 0,66 \\
\hline & & & Pembiayaan & 0,33 & 2 & 0,66 \\
\hline & & & Partisipasi Masyarakat & 0,33 & 2 & 0,66 \\
\hline
\end{tabular}

Sumber: Hasil Analisa, 2021

Berdasarkan hasil analisis skoring pada tabel 4 dapat diketahui bahwa perolehan skor total mengenai kondisi aksesibilitas wisata di Kabupaten Karanganyar bagian Timur dalam upaya mengintegrasikan obyek wisata adalah 11.06. Berdasarkan pengelompokan tingkat kesiapan pada tabel 2, maka termasuk pada tingkat kesiapan sedang karena berada pada interval 8,34-11, 67 .

\section{KESIMPULAN}

Kesiapan Aksesibilitas Wisata di Kabupaten Karanganyar bagian Timur dalam Mengintegrasikan Obyek Wisata, hanya mendapat poin sebesar 11, 06, yang artinya memiliki tingkat kesiapan sedang.

Terdapat 5 Sub Variabel $(33,3 \%)$ yang memiliki tingkat kesiapan tinggi diantaranya sarana transportasi umum menuju DTW, Sarana Parkir, Waktu perjalanan, Jaringan Jalan dan Informasi (rambu petunjuk arah).
Selanjutnya terdapat 8 Sub Variabel $(53,3 \%)$ yang memiliki kesiapan sedang yaitu Sarana transportasi umum dari dan menuju ke bandara, terminal dan bandara, sarana transportasi umum yang aman dan nyaman, Rute angkutan umum, Pusat informasi, Stake holder, pembiayaan dan partisipasi masyarakat. Sisanya sebanyak 2 sub variabel $(13,4 \%)$ memiliki tingkat kesiapan yang rendah yaitu Akses Multimoda dan Ketepatan waktu kedatangan angkutan umum.

Kedua hal tersebut harus menjadi prioritas bagi Pemerintah Kabupaten Karanganyar dalam penyelenggaraan aksesibilitas wisata sehingga mampu mewujudkan integrasi antar obyek wisata. Untuk itu, dibutuhkan peningkatan integrasi antar moda transportasi mulai dari angkutan jalan, angkutan kereta api serta angkutan udara baik trayek maupun non trayek yang ada di dalam maupun di luar kawasan penelitian, terutama untuk 
menjangkau obyek-obyek wisata yang berada pada lokasi yang cukup ekstrem agar lebih mudah dikunjungi oleh wisatawan. Serta diperlukan pengaturan yang lebih ketat mengenai jam kedatangan dan operasional angkutan umum secara lebih terstruktur dan terorganisir, sehingga wisatawan di Kabupaten Karanganyar bagian Timur dapat melakukan perjalanan wisata secara lebih nyaman, cepat dan efisien.

Terdapat 3 jenis integrasi yang terbentuk dalam penyelenggaraan aksesibilitas wisata di Kabupaten Karanganyar bagian Timur yaitu Integrasi secara fisik, Integrasi secara Informasi dan Integrasi Koordinasi

\section{UCAPAN TERIMAKASIH}

Peneliti mengucapkan terima kasih terhadap surveyor, DISPARPORA dan DISHUB-PKP Kabupaten Karanganyar yang telah memberikan data, Wisatawan serta Universitas Sebelas Maret Surakarta sehingga penelitian ini dapat berjalan dengan lancar.

\section{REFERENSI}

Bowersox, D., Closs, D., \& Cooper, M. B. (2013). Supply Chain Logistics Management (4th Editio). Singapore :McGraw-Hill.

Chaplin, J. P. (2006). Kamus Lengkap Psikologi. Jakarta :Raja Grafindo Persada.

Dinas Kominfo Jateng. (2017). Salahi Izin Trayek, Dua Bis Terpaksa DikandangkaN - Pemerintah Provinsi Jawa Tengah. 15 Juni. Retrieved January 10, 2020, from https://jatengprov.go.id/beritadaerah/sal ahi-izin-trayek-dua-bis-terpaksadikandangkan/

Diskominfo. (2017). Kabupaten Karanganyar Raih Piala WTN 2016 Bidang Lalu Lintas. Www.Karanganyarkab.Go.Id. Retrieved January 10, 2020, from https://www.karanganyarkab.go.id/2017 0131/kabupaten-karanganyar-raih-pialawtn-2016-bidang-lalu-lintas/

Hamidin, D., \& Surendro, K. (2010). Model Supply Chain Management Dalam Perspektif Teknologi. Seminar Dan Call For Paper Munas Aptikom Polliteknik Telkom, 36-43.
Hari, K. (1997). Kepariwisataan. In Kepariwisataan (pp. 21-27). Jakarta: Grasindo.

Kunjana, G. (2016). Objek Wisata Harus Terintegrasi Angkutan. Www.Investor.Co.Id. Retrieved January 11, 2020, from https://investor.id/national/objek-wisataharus-terintegrasi-angkutan

Mantovani, C. (2021). Ish Ish Ish... 50\% Jalan di Karanganyar Rusak. Solopos.Com. Retrieved February 21, 2021, from https://www.solopos.com/ish-ish-ish-50jalan-di-karanganyar-rusak-1107608

Nations, U., \& Programme, E. (2005). Making Tourism More Sustainable - A Guide for Policy Makers (English version). Making Tourism More Sustainable - A Guide for Policy Makers (English Version). https://doi.org/10.18111/978928440821 4

RTRW Kabupaten Karanganyar Tahun 20132032, (2013). Retrieved January 18, 2020, from http://perpustakaan.bappenas.go.id/lonta r/opac/themes/bappenas4/templateDetail .jsp?id=164251\&lokasi=lokal

PP No. 50 Tahun 2011 tentang Rencana Induk Pembangunan Kepariwisataan Nasional Tahun 20102025 [JDIH BPK RI]. Retrieved January 20, 2021, from https://peraturan.bpk.go.id/Home/Detail s/5183/pp-no-50-tahun-2011

Sahla, H. M. H. (2017). Pengaruh Daya Tarik Dan Aksesibilitas Terhadap Minat Berkunjung Wisatawan Ke Air Terjun Ponot Di Desa Tangga Kecamatan Aek Songsongan Kabupaten Asahan. 11511160. https://doi.org/10.31227/osf.io/mz5gy

Sasmita, I. (2019). Kabupaten Karanganyar, Fasilitas Transportasi Umum Bagi Pelajar Bumi Intan Pari. Karanganyarkab.Go.Id. Retrieved January 14, 2020, from https://www.karanganyarkab.go.id/2019 1204/fasilitas-transportasi-umum-bagipelajar-bumi-intan-pari/

Setiadi, A. (2017). Sepi Penumpang, Banyak Angkutan di Karanganyar Tak Jalan. Www.Daerah.Sindonews.Com.

Retrieved January 14，2020， from 
https://daerah.sindonews.com/berita/116 8793/22/sepi-penumpang-banyakangkutan-di-karanganyar-takjalan? showpage $=$ all

Simanjuntak, C., Leli Kusuma Dewi, L. G., \& Susrami Dewi, N. G. A. (2018). Penyediaan Aksesibilitas Bagi Wisatawan Penyandang Disabilitas Oleh Stakeholder Di Kotamadya Denpasar Kecamatan Denpasar Selatan. Jurnal IPTA, 6(1), 55 . https://doi.org/10.24843/ipta.2018.v06.i 01.p06

Spillane, J. J. (1987). EKONOMI PARIWISATA : Sejarah dan Prospeknya. Yogyakarta :Kanisius.

Sumarsono, A. (2014). CANDI CETHO Sepi Pengunjung. Www.Solopos.Com. Retrieved January 14, 2020, from https://www.solopos.com/candi-cethosepi-pengunjung-200597

Susantoro, B., \& Parikesit, D. (2004). 1-2-3 Langkah: Langkah Kecil yang Kita Lakukan Menuju Transportasi yang Berkelanjutan. Majalah Transportasi Indonesia, 1, 89-95.

Suwantoro, G. (2004). Dasar-dasar Pariwisata (p. 15). Yogyakarta :Andi.

Thynell, M. (2009). Expert Consultation on Transport Methodology UNDESA New York Social indicators for public transport. Retrieved January 16, 2020, from

https://www.un.org/esa/dsd/susdevtopic s/sdt_pdfs/meetings/ecm0609/Marie_Th ynell.pdf

Wearing, S., \& Mc Donald, M. (2002). The development of community-based tourism: Re-thinking the relationship between tour operators and development agents as intermediaries in rural and isolated area communities. Journal of Sustainable Tourism, 10(3), 191-206. https://doi.org/10.1080/0966958020866 7162 